
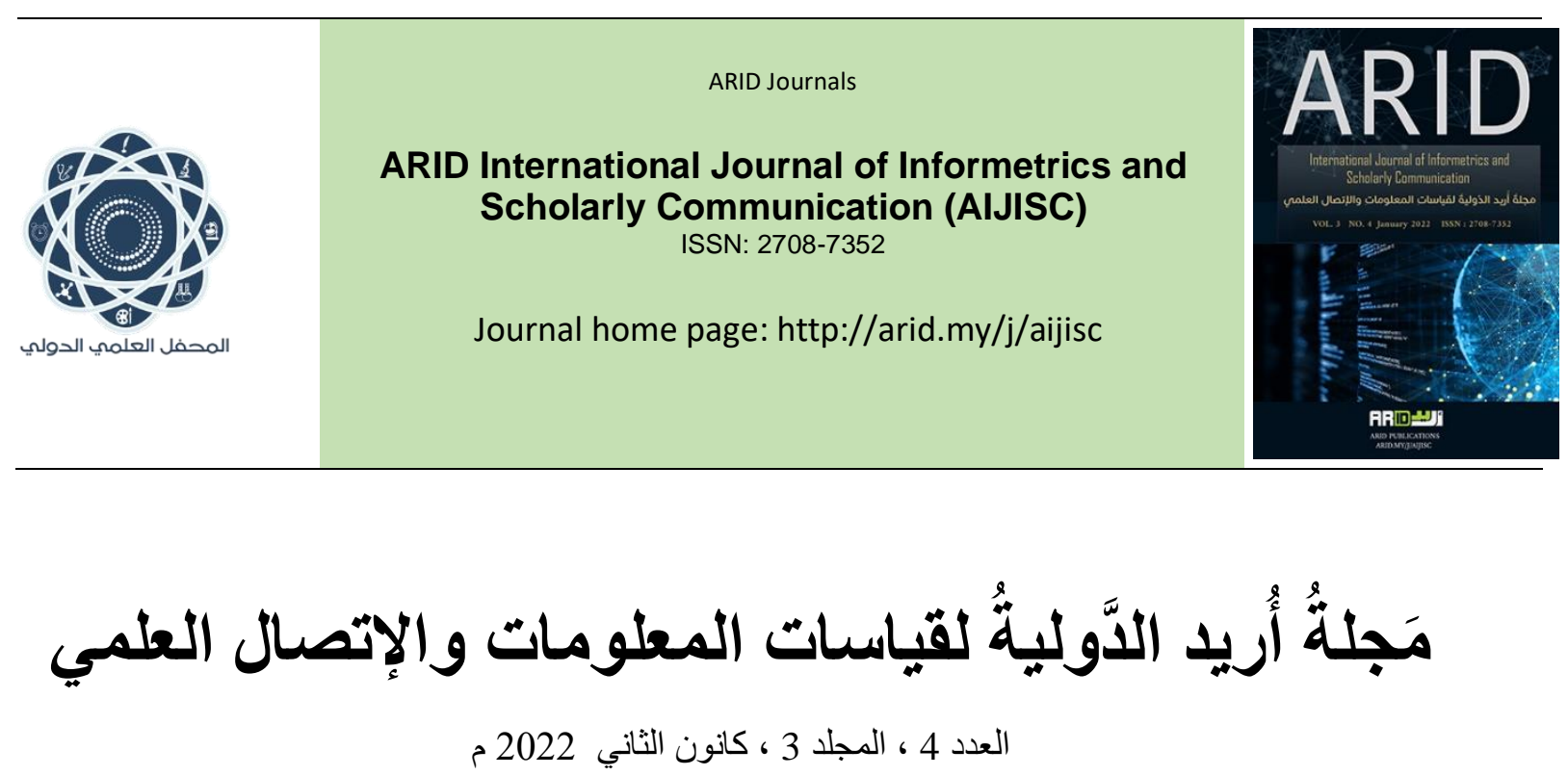

\title{
Arab Scholars' Perceptions on The Quality, Reliability, and Adequacy of Arabic Digital Content
}

\author{
Ahmed Maher Khafaga Shehata*, Khalfan Zahran Al Hijji, Jamal Alsalmi, Nour Eldin \\ Mohamed Elshaiekh \\ Department of Information Studies - Sultan Qaboos University - Oman \\ استطلاع رأي الباحثين العرب حول جودة وموثوقية وملاعمة المحتوى الرقمي العربي \\ أحمد ماهر خفاجة شحاتة**، خلفان بن زهران الحجي، جمال بن مطر السالمي، نور الدين محمد الثيخ \\ قسم در اسات المعلومات ـ كلية الآداب و العلوم الاجتماعية ـ جامعة السلطان قابوس- عُمان \\ a.shehata@squ.edu.om \\ arid.my/0005-6016
}

https://doi.org/10.36772/arid.aijisc.2022.348 


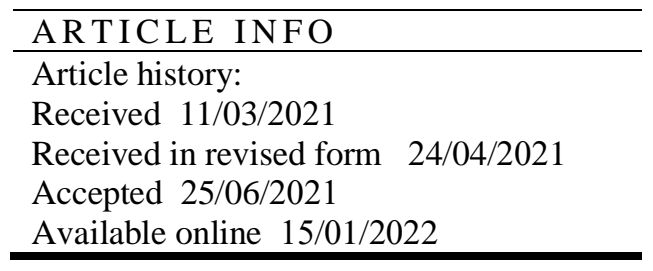

\begin{abstract}
Despite the availability of millions of information resources on the internet, the Arabic digital content represents a relatively small percentage compared with the information available in other languages. The size of Arabic content, the lack of an adequate number of Arabic databases that organize this content and make it available to the Arab reader, and the lack of novelty and originality are the main issues that feature the Arabic content on the internet. The aim of the current study is to clarify the Arab scholars' perception regarding the quality, reliability, and suitability of Arabic digital content that is available on the internet. A quantitative approach was adopted in this study in order to answer the research questions. A questionnaire was distributed online among a sample of Arab scholars to determine the quality and reliability of the Arabic digital content. Moreover, the questionnaire tried to identify the extent to which the current Arabic digital content meets the growing information needs, to identify the Arab scholars' uses of Arabic content, and to discover the criteria that determine the digital content suitability. The findings of this study revealed that Arab scholars believe that Arabic digital content is weak and there is a lack of originality. In addition, the results indicated that Arabic digital content on the internet does not satisfy the scholars' needs which enforce them to use English information resources to compensates for the lack of Arabic resources. The study recommended the necessity of establishing mechanisms to support Arabic digital content and increase the academic institutions' role in enhancing Arabic digital content by encouraging and supporting scholarly research in the Arabic language.
\end{abstract}

Keywords: Digital content, Information needs, Information resources , Arabic language, Scholarly content. 


\section{الملخص}

رغم ملايين مصادر المعلومات المتاحة على شبكة الإنترنت إلا أن المحتوى الرقمي العربي يمثل قدرًا ضئيلا بجانب

غيث المعلومات المنو افرة بلغات أخرى. ونظرًا لأن المحتوى الرقمي العربي يعاني من مشكلات متعددة منها أنه لا يمكن أن يقارن بالمحتوى المتاح بلغات أخرى وعدم وجود منافذ متعددة تنظّم هذا المحتوى وتتيحه للقارئ العربي، بالإضافة إلى عدم حداثته وضعفه فقد سعت الدراسة الحالية للتعرف على رأي الباحثين العرب حول جودة وموثوقية وملاءمة المحتوى الرقمي العربي المتاح على شبكة الإنترنت. قامت الدراسة الحالية باستخدام المنهج الكمي من خلال استخدام أداة الاستبانة لتحقيق أهداف الدر اسة والتي تمثلت في تحديد مدى جودة وموثوقية المحتوى الرقمي العربي، التعرف على مدى تلبية المحتوى الرقمي العربي الحالي للاحتياجات المعلوماتية المتنامية، التعرف على استخدامات الباحثين العرب للمحتوى العربي و اكتشاف المعايير التي تحدد مدى ملاءمة المحتوى الرقمي للباحثين العرب. وقد بلغ عدد المشاركين في الاستبانة 98 مشاركا. وقد خلصت الدر اسة إلى ضعف و عدم ملاءمة مصادر المعلومات المتاحة باللغة العربية للباحثين العرب بالإضافة إلى قلة مجالات توظيف المحتوى الرقمي العربي وحاجة الباحثني للمحتوى المتاح باللغة الإنجليزية كونه بديلا لضعف المحتوى العربي. وأوصت الدر اسة بضرورة وضع آليات لاعم المحتوى الرقمي العربي وزيادة اهتمام المؤسسات بتفعيل دور البحث العلمي في تعزيز المحتوى المعرفي الرقمي العربي بتشجيع ودعم البحوث العلمية العربية.

الكلمات المفتاحية: المحتوى الرقمي، الاحتياجات المعلوماتية، مصادر المعلومات، اللغة العربية، المحتوى العلمي. 
ساهدت ثورة الإنترنت في تعزيز الفهم العالمي المشترك للقضايا المعلوماتية من خلال المحتوى الذي ينشر باللغات العالمية في صيغة مقالات علمية أو تقارير وحوار ات أو غبر ها من أثكال المعلومات المختلفة. ونتيجة لهذا الدور الكبير للمحتوى المنشور على الإنترنت، فإن العديد من الدول المتقدمة وضعت استر اتيجيات واضحة لتعزيز حضور ها على الإنترنت من خلال تعزيز المحتوى المنشور بلغاتها والمعبر عن ثقافاتها كماً وكيفاً. ولذلك بادرت الجامعات والمؤسسات العلمية والبحثية والمجتمعية، بالإضافة إلى الأفراد في نشر المحتوى الرصين وإتاحته للعامة على الإنترنت. ونتيجة لهذه الجهود نجد أن المحتوى المنشور على الإنترنت ينمو باضطر اد منسارع. إلا أن هذه الجهود المبذولة تتفاوت بين الدول والثقافات وهو ما ينعكس على نوعية المحتوى المنشور. فبينما نجد كماً هائلاً باللغة الإنجليزية واللغات الأوروبية و الروسية و الصينية نجد ضعفاً ملحوظاً في المحتوى العربي المنشور. يضاف إلى ضعف المحتوى العربي افتقاده إلى الدقة والموثوقية والتنوع في المجالات العلمية المختلفة. ولذلك تهذف هذه الدر اسة إلى استطلاع وجهات نظر الباحثين العرب حول المحتوى العربي المنشور من حيث جودته ومدى ملاعمته

يكتسب موضوع المحتوى الرقمي العربي أهمية كبيرة نتيجة وجود حاجة ماسة من قبل الباحثين العرب إلى إيجاد محتوى علمي يخدم احتياجاتهم البحثية ويغطي موضو عات متنو عة باللغة العربية. وفي الحقيقة رغم وجود محتوى علمي هائل باللغات الأخرى إلا أن اللغة العربية كونها لغة يتحدث بها ملابين البشر ماز الت تعاني من عدم الاهتمام بها كلغة رئيسية للبحث العلمي في الوطن العربي، ولذلك تسعى الدر اسة الحالية لإبر از تصور ات الباحثين العرب حول المحتوى الرقمي العربي المتاح على شبكة الإنترنت

$$
\text { وذللك في مسعى للتعرف على و اقع المحتوى الرقمي العربي على شبكة الإنترنت. }
$$

مشكلة الار اسة وتساؤلاتها:

مع الأهيّة المتزايدة للمحتوى الرقمي، ورغم وجود ملايين مصادر المعلومات على شبكة الإنترنت إلا أن المحتوى الرقمي العربي يمثل قدرًا ضئيلا بجانب غيث المعلومات المنوافرة بلغات أخرى. ولا يعد حجم المحتوى الرقمي العربي المنشور على شبكة الإنترنت الإشكالية الوحيدة المرتبطة به، بل يرتبط المحتوى الرقمي العربي بإنثكاليات أخرى متنوعة منها: جودة المحتوى، 
ARID International Journal of Informetrics and Scholarly Communication (AIJISC) VOL: 3, NO 4, January 2022

إمكانية الوصول إلى المحتوى، أصالة المحتوى، و أيضا دقة ذلك المحتوى واحتو ائه على معلومات خاطئة وعدم موثوقية بعض مصادر المعلومات.

ورغم حجم المحتوى العربي الضئيل نِسِبِيَّا على شُبكة الإنترنت إلا أننا نجد تنوعًا في المحتوى ما بين محتوى تتقيفي وتعليمي وبحثي وترفيهي مما يجعله مفيدًا لفئات مختلفة من مستخدمي الشبكة العنكبوتية. ورغم ذلك التنوع، إلا أن عددًا ليس بالقليل من مستخدمي الشبكة العنكبوتية يتجنبون استخدام المحتوى العربي على الثبكة ويفضلون اللجوء إلى مصادر المعلومات المتو افرة باللغة الإنجليزية نظرًا لتنو عها ووفرتها وسهولة الوصول إليها مما يجعل الإقبال على استخدام المحتوى العربي ضئيلا مقارنة بالمحتوى المتو افر باللغة الإنجليزية حيث يمثل المحتوى العربي نسبة تعادل فقط 3\% من المحتوى الكلي (محمود، 2011) وحتى من هذه النسبة البسيطة نصفها تقريبا يفتقر الموثوقية مما يؤثر سلبًا على اعتمادها و استخدامها من قبل الباحثين العرب. ورغم إحجام عدد كبير من الباحثين عن اللجوء إلى المحتوى الرقمي العربي كمصدر للمعلومات، إلا أنه لا يوجد در اسات تتاولت دو افع الباحثين العرب لتجنب المحتوى العربي و اللجو ء لمصادر بلغات أخرى، مما يدعو إلى إجر اء دراسات عربية تهدف للتعرف على آراء الباحثين العرب حول المحتوى الرقمي العربي على شبكة الإنترنت من حيث الجودة والأصالة والإتاحة وإمكانية استخدام ذللك المحتوى و الاعتماد عليه لأغر اض بحثية.

تساؤلات الاراسة:

تتناول الدراسة الحالية آراء الباحثين العرب حول جودة وملاءمة المحتوى العلمي الرقمي العربي واستخدامهم لذلك المحتوى كداعم لعملية البحث العلمي. وتطر ح الدر اسة عدد من التساؤلات أهمها:

1. ما مدى جودة وموثوقية المحتوى الرقمي العربي على شبكة الإنترنت من وجهة نظر عينة الدراسة؟

2. ما مدى تلبية المحتوى الرقمي العربي للاحتياجات و الخدمات المعلوماتية المتنامية للباحثين العرب؟

3. ما استخدامات عينة الدراسة من الباحثين للمحتوى الرقمي العربي على شبكة الإنترنت؟

4. ما هي المعايير التي تحدد ملاعمة المحتوى الرقمي للاعتماد عليها كمصدر للمعلومات للباحثين العرب؟ 
ARID International Journal of Informetrics and Scholarly Communication (AIJISC) VOL: 3, NO 4, January 2022

\section{أهداف الاراسة:}

1. تحديد مدى جودة وموثوقية المحتوى الرقمي العربي من وجهة نظر الباحثين العرب.

2. معرفة مدى تلبية المحتوى الرقمي العربي الحالي للاحتياجات والخدمات المعلوماتية المتنامية للباحثين العرب. 3. التعرف على استخدامات الباحثين العرب للمحتوى العربي الرقمي على شبكة الإنترنت.

4. اكتشاف المعايير التي تحدد مدى ملاءمة المحتوى الرقمي للاعتماد عليها كمصدر للمعلومات للباحثين العرب.

\section{الاراسات السابقة:}

يشير الإنتاج الفكري العربي إلى وجود عدد من الدراسات الموجهة لقياس واستطلاع المحتوى الرقمي العربي وأنو اعه ومدى الإفادة منه، إلا أن الغالب على نلك الدراسات التركيز على جو انب النشر والإتاحة ومنصات التخزين دون التركيز على جودة المحتوى وملاءمته للأنشطة العلمية و البحثية للجامعات ومؤسسات البحث العلمي. وعلى الرغم من تنوع الجوانب التي استكثفت فيها الدراسات هذا الموضوع إلا أنها اتفقت على ضعف المحتوى الرقمي العربي على الإنترنت مقارنة بعدد المتحدثين باللغة العربية. فعلى الرغم من أن عدد المتحدثين باللغة العربية يزيد عن 421 مليون نسمة مشكلين نسبة 5,6\% من سكان العالم وفق إحصاءات مستخدمي الإتنرنت في العالم (2017) إلا أن المحتوى الرقمي العربي على الثبكة العالمية للمعلومات لم يتجاوز 3\% من المحتوى الرقمي العالمي، ولم يرتفع أكثر من ذلك منذ عام

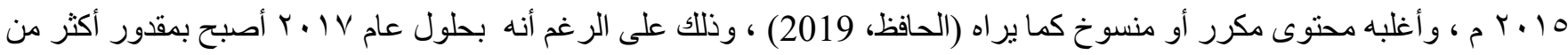

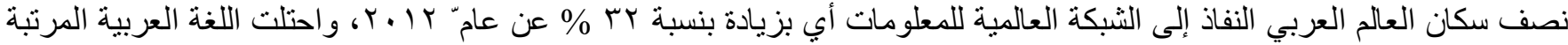
الرابعة بين اللغات العشرة الأكثر استعمالا على الثبكة عام ب ا ب (الحافظ، 2019). و على الرغم من وجود تفاوت في الكم و الإتاحة بين المحتوى" الرقمي العربي وأنواع المحتوى الأخرى مما أثر على الانتشار" والاستخدام، إلا أن التطور السريع والانفتاح والعولمة، مع ما يصاحبها من مردود اقتصادي وتتموي للمجتمعات، أصبحت من العوامل الملحة لضرورة وجود المحتوى الرقمي العربي على الخريطة

$$
\text { العالمية (بادي وبادي، 2020). }
$$

ويثير السالم (2012) إلى أن الاهتمام الجاد بالمحتوى الرقمي العربي يعود إلى 2003 حيث انعقدت القمة العالمية لمجتمع المعلومات في جنيف، وكان من ضمن توصياتها لبناء مجتمع المعلومات، أنه لابد من تعزيز المحتوى الرقمي والسعي لتطوير محتوى محلي يتلاءم مع الاحتياجات المحلية من حيث اللغة والثقافة نظر اللتأثير الإيجابي للمحتوى في التتمية الاقتصادية و الاجتماعية، وذلك انطلاقا من ضرورة بناء مجتمع المعلومات على أسسا احترام الهوية الثقافية والتنوع الفكري و اللغوي. وتسهم الدول العربية في إنتاج وصناعة المحتوى الرقمي 
من خلال الجامعات ومر اكز البحث العلمي ومؤسسات المعلومات، إلا أن ذلك المحتوى محدود جدا وليس متاحا للجميع ويفتقد أكثره إلى الصبغة العلمية والتقنية (السالم، 2012).

ولعل تأخر اللغة العربية في مسايرة النظور العلمي للنشر الرقمي وبناء محتوى علمي يوصل إلى مجتمع المعرفة المنشود مرده تهميش اللغة من أصحابها الذين انصرفوا عنها في كثير من مجالات الحياة في التجارة والصناعة والتعليم والبحث العلمي إلى لغات أخرى حتى وجنا بلدانا عربية تتجه نحو لغات أجنبية في التعليم العالي، خاصة في مجال التخصصات العلمية والتقنية (جمعة، 2017). ونظرا للواقع الذي يعيشه العالم العربي من ضعف المحتوى الرقمي العربي الذي يسهم به في المحتوى الرقمي العالمي، وانصراف عدد كبير من الباحثين العرب إلى التراث الفكري للغات أخرى للبحث و التطوير، فقد اتجهت كثير من الدراسات العربية إلى تثخيص هذا الو اقع و المشاكل و الصعوبات التي أدت إليه. واختلفت تلك الدراسات في تعرضها للإنكالات التي تواجه المحتوى الفكري العربي على الإنترنت وسبل تطويره إلى مسارات شنى، فمنها ما اتجه إلى الجانب التقني وتأخره في العديد من الدول العربية (حسني وبن السبتي، 2018؛ بن السبتي وبن السبتي، 2017؛ السالم، 2011)، ومنها ما أنشار إلى التعليم وضعف مساهمته في تكوين شخصيات علمية ناقدة قادرة على التحليل والتفكير العلمي، إضافة إلى انتشار الأمية في الكثير من البلاد العربية. ثم تحول كثير من الجامعات ومؤسسات التعليم العالي في الدول العربية إلى لغات أخرى للتنريس و البحث العلمي مما يجعل الباحثين العرب مدفو عين إلى الكتابة والنشر بتلك اللغات مما يضعف

$$
\text { مساهمنهم في الإنتاج الفكري الرقمي العربي (جمعة، 2017). }
$$

ومن أبرز المشكلات التي اتقتت عليها أغلب الدراسات هي: غياب استراتيجية عربية لصناعة المحنوى الرقمي العربي، حيث تغلب على المشاركات العربية على الإنترنت الجهود الفردية لأفر اد أو مؤسسات مختلفة دون الاسترشاد بضو ابط أو معايير لنوع المحتوى الرقمي أو حدو ده أو طرق إتاحته. ونتج عن ذلك ضعف كفاءة المبادرات الحكومية في مجال الرقمنة وتطوير المحتوى الرقمي على المستويين العربي و الإقليمي (بادي وبادي، 2020؛ حسني وبن السبتي، 2018؛ السالم، 2011). وربما مرد ذلك إلى إثكالية أخرى تطرق إليها بعض الباحثين تتمثل في ضعف التثريعات والقو انين المتعلقة بالملكية الفكرية وحقوق النشر و التأليف (جمعة، 2017؛ حسني وبن السبني، 2018). ويرى السالم (2011) أنه على الرغم من وجود العديد من التجارب والمشاريع والمبادرات في مجال إثراء المحتوى الرقمي العربي، إلا أنها تو اجه بعض التحديات التي تعوق انطلاقها متل ترجمنها إلى مشاريع فاعلة وملموسة، الأمر الذي يستدعي وجود خطة استر اتيجية موحدة لدعم اللغة العربية في شبكة الإنترنت وجطها أكثر فاعلية في التواصل العلمي. وعلى الرغم من مرور عقد من الزمن على تاريخ نشر الدراسة أعلاه إلا أن بعض هذه المشاكل والتحديات ماز ال موجودا حتى الآن و هذا ما أكدته دراسة بادي وبادي (2020) المنشورة 
حديثاو التي أكدت أن تأخر المحتوى الرقمي العربي يعود لأسباب عدة من أهمها: غياب رؤية استراتيجية عربية للمحتوى الرقمي؛ ضعف البنيةٌ التحتية و التكنولوجية لدى الكثير من الدول العربية؛ وقصور البنية التشريعية والتنظيمية اللازمة لحماية المحتوى الرقمي وتطويره، إضافة إلى ضعف الاستثمار في البحوث والتطوير، وضعف الحوافز لإنتاج المحتوى الإبداعي. وبالنسبة لخصوصية اللغة العربية وقدرة البرمجيات المختلفة على التعامل معها أظهرت دراسة زايدي (2018) أن اللغة العربية بتركيتها المعقدة تستدعي تعاملا خاصـا من قبل برمجيات البحث و الاسترجاع. فعلى الرغم من تزايد حجم المحتوى العربي على الثبكة وتنو عه إلا أنه ما زال يواجه صعوبات قضايا المعالجة و التنظيم من قبل بر امج التخزين والاسترجاع. فآليات بناء اللغة العربية ودلالات التر اكيب اللغوية والنحوية تتطلب فهما عميقا من المبرمجين ومطوري محركات البحث.

وبين بن جامع وسهيلة (2019) في دراستهما "صناعة المعلومات الإكترونية: در اسة من خلال التجارب العربية والدولية" أنه على الرغم من تطور المحتوى الرقمي على الإنترنت إلا أن العديد من دول العالم الثالث و الدول العربية ماز ال معتمدا على استير اد المحتوى الرقمي وتقنيات المعلومات، وذلك بسبب تأخر الجهود و المشاريع المنجزة لصناعة المعلومات في هذه الدول. ولخّصـا أسباب ذلك في أربعة عو امل: الفجوة الاقتصادية، فعلى الرغم من قدرة الدول ذات الاقتصاد المرتفع على توفير منطلبات صناعة المعلومات و إتاحتها تبقى العديد من الدول التي لا تضع ذلك في مقدمة أولوياتها نظر الكلفته العالية على اقتصاداتها ووجود مجالات أخرى في الر عاية الاجتماعية قد تكون أكثر إلحاحا منها. ويأتي المستوى التعليمي في المرتبة الثانية من العوامل وذللك لضعف بنية التعليم في دول العالم الثالث وهجرة العقول التي يمكن أن تساهم في رقي المحتوى العلمي منها. و العامل الثالث هو غياب أو ضعف المنظمات المعلوماتية المختصة في هذه الدول. و العامل الأخير هو ضعف مر اكز المعلومات في هذه الدول على تقديم خدمات معلومات متميزة. ومن المعوقات التي تواجه انتشار المحتوى العربي على الإنترنت والاستفادة منه ضعف التصميم والعناية بالمواقع وضعف المحتوى المنشور فيها و عشو ائيته، وركاكة اللغة وضعفها في محتويات كثير من المواقع. فالتصميم الذكي وسهولة النفاذ للموقع يعتبر من العوامل الأساسية للاستفادة من محتو ياته، وبغياب ذلك يخسر الموقع عددا من متابعيه والمستفيدين من خدماته. كما أن جودة المحتوى وملامسته لاحتياجات المستفيدين وكتابته بلغة عربية سليمة خالية من الأخطاء، يرفع من ثقة الباحثين و الر اغبين في الإفادة من المحتوى الرقمي العربي (الحافظ، 2019).

ويلاحظ بشكل واضح من استعر اض الدر اسات أعلاه أن التحليل الذي قدمه أغلب الباحثين للمحتوى الرقمي العربي خلص إلى نتيجة مفادها أن اللغة العربية، رغم غناها بالمفردات وسعة انتشار ها وقوة بنيتها و أصالة وجودها وبعدها التاريخي مما يؤ هلها لقيادة العالم في مجال العلم والمعرفة، إلا أنها تو اجه العديد من التحديات لفرض نفسها في الواقع الرقمي لأسباب بعيدة عن جو هرها، كالتراجع التقني والاقتصادي 
و السياسي للدول العربية وتخلفها في مجالات العلم والمعرفة. ومن هنا فقد انبرت كثير من الدراسات لتقديم الحلول والدقترحات لرفع المحتوى العربي على الإنترنت وتحسين مساهنه في المحتوى الرقمي العالمي. حيث برى علوي ومسروة (2017، 2020) أن المحتوى الرقمي العربي بحاجة إلى استر اتيجيات ومبادر ات لمواجهة التحديات التي تواجد اللغة العربية على شبكة الإنترنت، ومن ذلك تطوير بو ابات مؤسسات المعلومات باعتبار ها من أهم قتوات التوزيع للمحتوى الرقمي و إدارته، ولذلك فإنه على هذه المؤسسات وخاصة الأكاديمية منها التشارك على المستوى المحلي والإقليمي لإنشاء بو ابة عربية تدعم نشر المحتوى الرقمي العربي على شبكة الإنترنت و العمل على تشجيع مبادرات الإبداع في المجال و إيجاد حاضنات تتبنى هذه الأفكار. ولتنفيذ ذلك لابد من تضافر الجهود لضمان حماية حقوق المؤلف والملكبة الفكرية للمصنفات العربية على الثبكة المعلوماتية (حسني و بن السبتي، 2018). ويؤكد بادي وبوخالفة، 2018) أن هناك إمكانيات كبيرة للتعاون بين الدول العربية، خاصة بلدان المغرب العربي التي شملتها دراستهما، في مجال تكنولوجيا المعلومات والتواصل لو تم تجميعها و التوفيق بين حاجياتها المختلفة ستوفر كثبرا من الجهـ والمال مع ضرورة إيجاد آلبات التنفيذ.

\section{منهج الاراسة:}

استخدت الدر اسة المنهج الكمي الإحصائي لجمع البيانات وتحليلها حيث تم توزيع استبانة على أعضاء هيئة التنريس في خمس دول (عمان، مصر، الأردن، الكويت والإمارات) عربية بجميع الكليات من خلال استخدام وسائل التواصل الاجتماعي مثل الو اتساب و الفيسبوك بالإضافة إلى إرسال الاستبانة من خلال البريد الإلكتروني. وتم تصميم الاستبانة باستخدام Google Forms وتم توزيع الاستبانة من شهر سبتمبر 2020 إلى شهر ديسمبر 2020. وقد تم الاعتماد على الدراسات السابقة باللغة العربية واللغة الإنجليزية في تصميم الاستبانة وروعي أن تكون محاور الاستبانة منوافقة مع الدراسات السابقة في الموضوع وقام بمراجعة الاستبانة متخصصين في المكتبات و المعلومات.

المرحلة الثانية قام الباحثون بتوزيع الاستبانة من خلال البريد الجامعي لأعضاء التدريس في الجامعات العمانية، مجموعات الو اتساب للباحثين في دول الخليج العربي، ومن خلال مجموعة أعضاء هيئة التتريس في الجامعات العربية على الفيسبوك وقد بلغ عدد المشاركين في الاستبانة 98 مشاركا. أيضا تمّ استخدام مقياس ليكرت الخماسي في جميع محاور الدراسة كونه يعطي بيانات أكثر دقة في التحليل.

وقد اشتملت الاستبانة التي وجهت لعينة الدراسة على (12) سؤالاً، مقسمة على ستة محاور:

المحور الأول : البيانات الديموغر افية. 
ARID International Journal of Informetrics and Scholarly Communication (AIJISC) VOL: 3, NO 4, January 2022

المحور الثاني: مصادر المحتوى الرقمي العلمي المتاح باللغة العربية على شبكة الإنترنت. المحور الثالث : موثوقية المحتوى الرقمي العلمي العربي على شبكة الإنترنت من وجهة نظر عينة الدراسة. المحور الرابع : تلبية المحتوى الرقمي العربي للاحتياجات والخدمات المعلوماتية المتنامية للباحثين العرب. المحور الخامس: استخدامات المحتوى الرقمي العربي على شبكة الإنترنت. المحور السادس : المعايير التي تحدد ملاءمة المحتوى الرقمي للاعتماد عليها كمصدر للمعلومات. وقد تم استخدام برنامج الحزم الإحصائية للعلوم الاجنماعية SPSS الإصدار (26) في المعالجة الإحصائية للبيانات وقد نم استخدام التكرار ات و المتوسطات الحسابية والانحر اف المعياري، و النسب المئوية، واختبار " ت " T-test بعد عمل لمعرفة أي فروق ذات دلالة إحصائية في استجابات عينة الدراسة وفقا لمتغير النوع وتصورات العينة حول المحاور المختلفة، واختبار تحليل التباين أحادي الاتجاه One Way ANOVA لمعرفة أي فروق ذات دلالة إحصائية في استجابات عينة الدر اسة وفقاً لمتغيرات الدرجة الأكاديمية و التخصص، وقام الباحثون بترنيب استجابات الششركين في الاستبانة تَنَازُليَّا حسب قيمة المتوسط الحسابي، وفي حلة تسلوي قيمة المتوسط الحسابي لأكثر من عبارة تم الاعتماد على قيمة الانحر اف المعياري.

\section{مجتمع وعينة الاراسة:}

اثتتمل مجتمع الدر اسة على الباحثين في خمسة دول هي عمان و الأردن ومصر و الإمار ات والكويت. وقد نمّ اختيار نلك الدول نظرًا لأنها تمثل مجمو عات مختلفة من الدول العربية أفريقية وخليجية وبلاد الثشام. وقد تم اختيار عينة الدراسة بشكل عشو ائي لضمان فرص حصول جميع أفر اد مجتمع الدر اسة على فرص منسلوية في الإجابة على الاستبانة. ومن الملاحظ أن جمع البيانات مر بثلاث مر احل:

- - المرحلة الأولى تجربة الاستبانة Pilot questionnaire :وقد تم في هذه المرحلة اختبار الاستبانة على مجموعة عثو ائية صغيرة (n=9) من أفر اد العينة للتأكد من مدى كفاءة استمارة الاستيان، ومدى صلاحيتها كأداة بحثية. - - المرحلة الثنية توزيع الاستبانة على عينة الدراسة في شهر سبتمبر. وقد نم في هذه المرطة توزيع الاستبانة على عينة الدر اسة في كلًا من مصر وسلطنة عمان. - - المر حلة الثالثةتوزيع الاستباتة على عينة الدراسة في الأردن والكويت والامارات و إعادة توزيع الاستبانة على عينة المرحلة الأولى لضمان الحصول على أكبر عدد من الاستجابات. 
ويلاحظ أنه رغم استخام عدد متتوع من الأنوات لتوزيع الاستبانة إلا أن عدد الاستبانات المسترجعة كان 98 مستجييا. ورغم أن العدد يعتبر قليل نسيًا إلا أن الفريق البحثي وُجد أنه ملائم كون الدراسة تسعى لاستكثاف الظاهرة وليس تعميم النتائج.

\section{التحليل والنتائج:}

تم استخدام برنامج SPSS26 لتحليل البيانات التي نمّ جمعها بالاستيبان، حيث تمّ تطبيق عدد من الاختبار ات الإحصائية مثل التكر ارات و الإحصاءات التحليلية وتحليل التباين Test للمقارنة بين المنوسطات بين المجموعات المختلفة من أجل التعرف على آر اء المستفيدين و التباين بينها و الإجابة على أسئلة الدراسة.

جدول (1) البيانات الديمو غر افية للمشاركين في الاستبانة

\begin{tabular}{|c|c|c|c|}
\hline النسبة & العدد & \multicolumn{2}{|c|}{ البيانات الايموغرافية } \\
\hline 58.2 & 57 & ذكر & \multirow[t]{2}{*}{ النوع } \\
\hline 41.8 & 41 & أنتى & \\
\hline 37.8 & 37 & عمان & \multirow[t]{5}{*}{ الدولة } \\
\hline 35.7 & 35 & مصر & \\
\hline 5.1 & 5 & الأردن & \\
\hline 17.3 & 17 & الكويت & \\
\hline 4.1 & 4 & الإمار ات & \\
\hline 14.3 & 14 & $21-30$ & \multirow[t]{5}{*}{ الفئة العمرية } \\
\hline 34.7 & 34 & $31-40$ & \\
\hline 32.7 & 32 & $41-50$ & \\
\hline 11.2 & 11 & $51-60$ & \\
\hline 7.1 & 7 & 61- & \\
\hline
\end{tabular}




\begin{tabular}{|c|c|c|c|}
\hline 12.2 & 12 & باحث & \multirow[t]{5}{*}{ الارجة العلمية } \\
\hline 28.6 & 28 & دراسات عليا & \\
\hline 35.7 & 35 & أستاذ مساعد & \\
\hline 13.3 & 13 & أستاذ مشارك & \\
\hline 10.2 & 10 & أستاذ أ & \\
\hline 19.4 & 19 & أقل من خمس سنو ات & \multirow[t]{4}{*}{ الخبرة } \\
\hline 24.5 & 24 & من ست لعشر سنوات & \\
\hline 23.5 & 23 & هن 11- 15 & \\
\hline 32.7 & 32 & أكثر & \\
\hline 100 & 98 & & المجموع \\
\hline
\end{tabular}

يوضح جدول (1) اليبانات الديموغرافية لعينة الدراسة؛ حيث مثّل الذكور نسبة 58.2\% من عينة الدراسة بينما مثل الإناث 41.8\% من عينة الدراسة. بينما تقدمت سلطنة عمان في عدد الباحثين الذين قامو ا بالإجابة على الاستبانة حيث أجاب 37 باحثا على الاستبانة بنسبة 37.8\% تلاها مصر بنسبة 35.7\% ثم الكويت والأردن و الإمارات بنسب 17.3\%، 5.1\% و 4.1\%. ينضح أيضا أن الفئة العمرية من 31-40 عام و أيضا من 41 -50 كانتا أكثر الفئات مشاركة في الاستبانة حيث مثلت نسبتهم 67.4 من عدد المشاركين في الاستبانة بينما كانت الفئة العمرية من 61 عام فأكثر هي أقل الفئات استجابة على الاستبانة. فيما يخص الدرجات العلمية للمشاركين في الاستبانة فقد مثل طلبة الدراسات العليا وفئة الأساتذة الدساعدين أكبر فئة في عدد المشاركين حيث كان مجموع من ينتمون للفتينين 63 فردا من أصل 98 فردا بنسبة 64.2\% من مجموع المشاركين في الرد على الاستبانة. كما لوحظ أن عددا كبير ا من المشاركين لايهم خبرة كبيرة في البحث حيث كان عدد من لايهم خبرة أكثر من 10 سنو ات في البحث العلمي 55 مشاركا. يوضح جدول (2) تصدر الششاركين في الاستبانة من كليات الآداب حيث شارك منهم أكثر من نصف المشاركين في الدراسة بنسبة 57.1 \% من إجمالي المشاركين، بينما تلتها كليات التربية في عدد المشاركين بنسبة \% 18.4 من العدد الكلي، ثم كليات 
الاقتصاد و المحاسبة بنسبة 13.3 \% من إجمالي العينة. أيضا لوحظ قلة عدد المشاركين من كليات الحقوق 2\% من العدد الكلي

$$
\text { وكليات العلوم } 9.2 \text { \% من العدد الكلي. }
$$

\begin{tabular}{|c|c|c|}
\hline النــسبة & العــد & الكــلية \\
\hline 57.1 & 56 & الآداب \\
\hline 18.4 & 18 & التربية \\
\hline 2.0 & 2 & الحقوق \\
\hline 9.2 & 9 & العلوم \\
\hline 13.3 & 13 & الاقتصـاد \\
\hline 100.0 & 98 & المجموع \\
\hline
\end{tabular}




\section{محركات البحث المستخدمة للبحث عن المعلومات العربية}

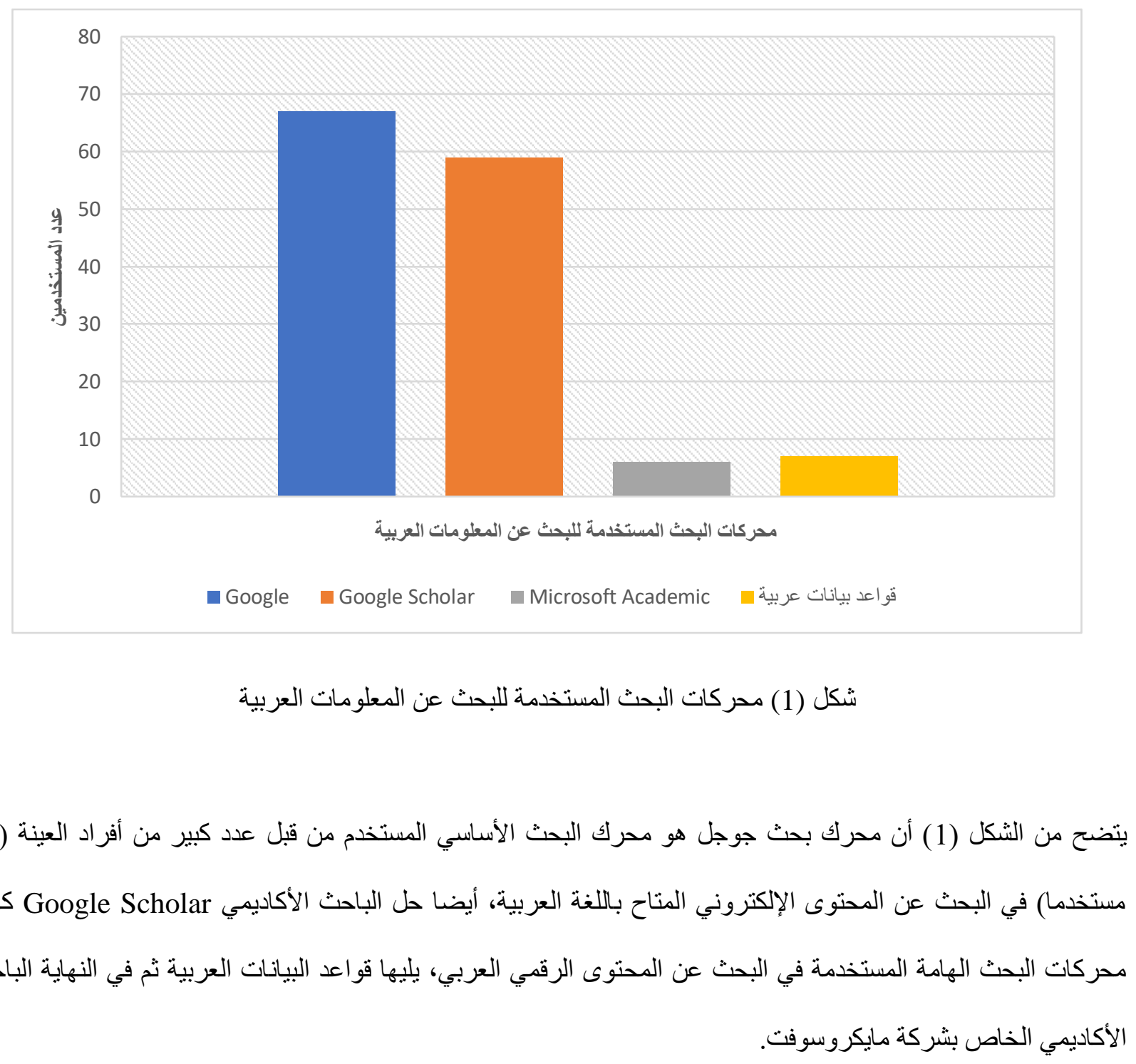


ARID International Journal of Informetrics and Scholarly Communication (AIJISC) VOL: 3, NO 4, January 2022

\section{مصادر المحتوى العلمي المتاح باللغة العربية على شبكة الإنترنت:}

يوضح جدول (3) مصادر المحتوى العلمي المتاح باللغة العربية على شبكة الإنترنت مرتبة وفقا للمتوسط حيث لوحظ أن جميع مصادر المعلومات حصلت على قيم متوسطة إلى ضعيفة مما بدل على أن مصادر المعلومات المتاحة باللغة العربية ضعيفة في مجمها. بالنظر إلى الجدول نجد أن أعلى تللك المصادر من حيث المتوسط هي الصحف حيث حصلت على منوسط 3.78، تلتها المدونات و المقالات العلمية بمتوسطات 3.64 و3.40 على التو الي.

أيضًا المتمعن في الجدول يلاحظ أن كلا من المجلات، الرسائل الجامعية، عروض الكتب، الكتب وقو اعد البيانات حصلت على متوسط أعلى من 3 لكن أفر اد العينة لم يتفقو ابشكل كامل أن تلك المصادر متاحة بشكل مرض على شبكة الإنترنت مما يدل على أنها حتى وإن كانت منو افرة فإنها غير متاحة بشكل يتناسب مع احتياجات المستفيدين. من جانب آخر نجد أن مصادر مثل المر اجعات العلمية، القو امبس، المخطوطات و الموسو عات حصلت على منوسطات ضعيفة من 2.47 إلى 2.96 مما يدل على أن تو افر ها على شبكة الإنترنت ضئيل أو معدوم. وبعمل اختبار T-test لكثف وجود فروق ذات دلالة إحصائية بين الذكور و الإناث للاطلاع على آر ائهم حول مصسادر المعلومات المتاحة باللغة العربية وجدت فروق ذات دلالة إحصائية في خمس عبار ات و هي "الموسو عات" حيث بلغت قيمة T 2.620- عند مستوى دلالي 0.011 و القو اميس حيث بلغت قيمة 3.413- عند مستوى معنوية 0.001 و المجلات حيث بلغت قيمة 2.096عند مستوى دلالي 0.039 ومر اجعات الكتب حيث بلغت قيمة T 3.231- عند مستوى دلالي 0.002 والمخطوطات حيث بلغت

$$
\text { قيمة T T } 0.047 \text { - 2.015- عند مستوى دلالي }
$$

جدول (3) مصادر المحتوى العلمي المتاح باللغة العربية على شبكة الإنترنت

\begin{tabular}{|c|c|c|}
\hline الانـحراف & المتوسط & مصادر المعلومات \\
\hline 1.021 & 3.78 & الصحف \\
\hline 1.151 & 3.64 & المدونات \\
\hline 1.146 & 3.40 & المقالات العلمية \\
\hline 1.167 & 3.29 & المجلات \\
\hline 1.045 & 3.14 & الرسائل الجامعية \\
\hline 1.131 & 3.09 & عروض الكتب \\
\hline
\end{tabular}




\begin{tabular}{|c|c|c|}
\hline 1.096 & 3.07 & الكتب \\
\hline 1.153 & 3.01 & قواعد البيانات \\
\hline .994 & 2.96 & المراجعات العلمية \\
\hline 1.071 & 2.81 & القواميس \\
\hline 1.063 & 2.72 & المخطوطات \\
\hline 1.010 & 2.62 & الموسوعات \\
\hline .997 & 2.47 & الوثائق \\
\hline .984 & 2.58 & أخرى \\
\hline
\end{tabular}

موثُوقية المحتوى الرقمي العلمي العربي على شبكة الإنترنت:

يلاحظ من جدول رقم (4) أنه هنالك توجه إيجابي من أفر اد العينة نحو مصداقية مصسادر المعلومات الأجنبية وتفوقها على مصادر المعلومات العربية حيث حصلت عبارة " المصادر العملية الأجنبية أكثر موثوقية من المصادر العربية" على منوسط 4.17 وهو يعتبر أعلى منوسط في العبار ات الخاصة بمصداقية المعلومات. أيضا يلاحظ أن هنالك بعض العبارات التي حصلت على عالي إلى حد ما مثل عبارة " كثير من ناشري المحتوى الرقمي العلمي العربي لا يهنمون بفص المحتوى لكثف الانتحال و أصالة المحتوى" بمتوسط 3.9 و عبارة " أر اجع المعلومات العلمية العربية المتاحة من خلال شبكة الإنترنت قبل استخدامها في در اساتي العلمية" التي حصلت على متوسط 3.79 مما يدل أن عينة الدر اسة متحفظة على جودة وأصلالة المحتوى الرقمي العربي. أيضا عبار ات مثل " أعتمد على مصادر عربية بعينها وأتجنب المصادر التي لا أعرف مدى موثوقيتها" حصلت منوسط 3.79 و عبارة "أر اجع المعلومات العلمية العربية المتاحة من خلال شبكة الإنترنت فبل استخدامها في التدريس" بمتوسط 3.78 بالإضافة إلى عبارة "مصادر المعلومات العربية على الإنترنت يكثر فيها الانتحال العلمي" وعبارة " كثير من المصادر العربية ينم نشرها دون التأكد من موثوقيتها" بمتوسط 3.74 والتي ندل على أن كثير من الباحثين يقومون بمراجعة الإنتاج الفكري العربي قبل استخدامه نتيجة عدم ثقتهم فيه.

من جانب آخر نجد أن عبارة "يمكن التأكد من صحة المعلومات العلمية العربية المنشورة على شبكة الإنترنت بسهولة" حصلت على متوسط 2.82 وعبارة " أثق في جميع مصادر المعلومات العربية العلمية على شبكة الإنترنت" بمتوسط 2.66 مما يدل 
ARID International Journal of Informetrics and Scholarly Communication (AIJISC) VOL: 3, NO 4, January 2022

على عدم اتفاق عينة الدر اسة مع كلتي العبارتين وتأكيدهم للعبار ات التي حصلت على منوسطات أكثر من 3 والتي تشكك في جودة وموثوقية المحتوى الرقمي العربي.

وبعمل اختبار test كثثف وجود فروق ذات دلالة إحصائية بين الذكور والإناث حول مصداقية مصادر المعلومات المتاحة باللغة العربية وجد فروق ذات دلالة إحصائية في عبارة واحدة وهي " مصادر المعلومات العربية على الإنترنت يكثر فيها

$$
\text { الانتحال العلمي" حيث بلغت قيمة } 0.105 T \text { عند مستوى دلالي } 0.023
$$

جدول (4) موثوقية المحتوى الرقمي العلمي العربي على شبكة الإنترنت

\begin{tabular}{|c|c|c|}
\hline الانحراف & المتوسط & 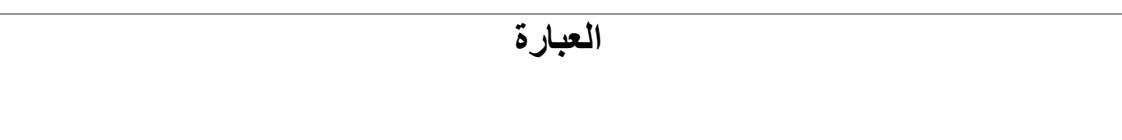 \\
\hline 1.046 & 4.17 & المصادر العملية الأجنبية أكثر موثوقية من المصادر العربية \\
\hline .891 & 3.90 & كثير من نانشري المحتوى الرقمي العلمي العربي لا يهتمون بفحص المحتوى لكثف الانتحال \\
\hline 1.008 & 3.79 & أر اجع المعلومات العلمية العربية المتاحة من خلال شبكة الإنترنت قبل استخدامها في \\
\hline 1.058 & 3.79 & أعتمد على مصادر عربية بعينها وأتجنب المصادر التي لا أعرف مدى موثوقيتها \\
\hline .936 & 3.78 & أر اجع المعلومات العلمية العربية المتاحة من خلال شبكة الإنترنت قبل استخدامها في \\
\hline 1.008 & 3.74 & مصادر المعلومات العربية على الإنترنت يكثر فيها الانتحال العلمي \\
\hline 1.048 & 3.74 & كثير من المصادر العربية يتم نشر ها بدون التأكد من موثوقيتها \\
\hline 1.133 & 3.70 & ألجأ إلى ترجمة المحتوى الرقمي غير العربي الموثوق به إلى اللغة العربية \\
\hline .982 & 3.60 & كثير من المصادر العلمية المتاحة باللغة العربية مترجمة من لغات أخرى \\
\hline .955 & 3.52 & أجد صعوبة في تحديد المنشئ الأصلي للعمل العربي المتاح على شبكة الإنترنت \\
\hline 1.002 & 3.08 & تتميز مصادر المعلومات العلمية العربية على شبكة الإنترنت بموثوقيتها العالية \\
\hline 1.078 & 2.82 & يمكن التأكد من صحة المعلومات العلمية العربية المنشورة على شبكة الإنترنت بسهولة \\
\hline .973 & 2.66 & أثق في جميع مصادر المعلومات العربية العلمية على شبكة الإنترنت \\
\hline
\end{tabular}




\section{تلبية المحتوى الرقمي العربي لاحتياجات الباحثين العرب:}

نجد أن العبار ات الخاصة "تلبية المحتوى العربي لاحتياجات الباحثين العرب" قد تباينت من جانب المتوسط. فنجد في جدول (5) أن العينة اتفقت مع عبارات مثل " المحتوى الرقمي المتاح بلغات أخرى كالإنجليزية أكثر وفرة وتنوعًا عن المحتوى العلمي العربي" بمتوسط 4.42 وعبارة " المحتوى العربي في قواعد البيانات العربية قليل مقارنة بقو اعد البيانات الأجنبية" بمتوسط 4.34 وأيضا عبارتي " ألجأ إلى المحتوى المتاح بلغات أخرى لعدم وجود ما أحتاجه باللغة العربية على شبكة الإنترنت ويوجد ندرة في المحتوى العربي العلمي في كثير من التخصصات العلمية" بمنوسط 4.08. بينما حصلت العبارة الخاصة بقلة قو اعد البيانات العربية على متوسط عالي نسبيا بقيمة 3.92 وأيضا العبارة الخاصة بتراجع المحتوى الرقمي العربي العلمي 3.69. نلاحظ أيضا وجود اتفاق بنسبة منوسطة حول أن هنالك صعوبة في الوصول إلى المحتوى الرقمي العربي على شبكة الإنترنت 3.57. من الملاحظ أن العبار ات الخاصة بتتوع المحتوى الرقمي العربي وتلبيته للاحتياجات البحثية قد حصلت على متوسطات ضعيفة تر اوحت بين 2.17 إلى 2.59. من الجدير بالذكر أنه بعمل اختبار الذكور و الإناث حول تلبية المحتوى الرقمي العربي لاحتياجات الباحثين العرب لم تسجل أي فروق إحصائية ذات دلالة بين المتوسطات.

جدول (5) تلبية المحتوى الرقمي العربي لاحتياجات الباحثين العرب

\begin{tabular}{|c|c|c|}
\hline الانحر اف المعياري & المتوسط & 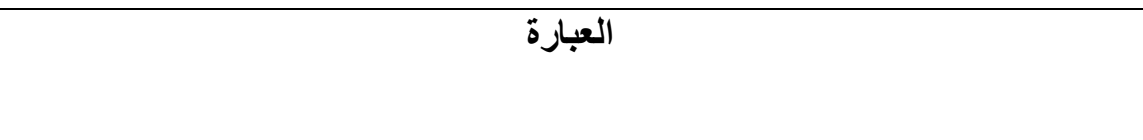 \\
\hline .962 & 4.42 & المحتوى الرقمي المتاح بلغات أخرى كالإنجليزية أكثر وفرة وتنوعًا عن المحتوى العلمي \\
\hline .984 & 4.34 & المحتوى العربي في قو اعد البيانات العربية قليل مقارنة بقو اعد البيانات الأجنبية \\
\hline 1.090 & 4.08 & ألجأ إلى المحتوى المتاح بلغات أخرى لعدم وجود ما أحتاجه باللغة العربية على شبكة \\
\hline 1.137 & 4.08 & يوجد ندرة في المحتوى العربي العلمي في كثير من التخصصـات العلمية \\
\hline 1.137 & 3.92 & قو اعد البيانات العربية في تخصصي قليلة ولا تغطي كافة احتياجاتي المعلوماتية \\
\hline 1.059 & 3.69 & و اقع المحتوى الرقمي العربي يشهد تر اجعاً ظاهرًا في اكتساب المعرفة \\
\hline
\end{tabular}




\begin{tabular}{|c|c|c|}
\hline .897 & 3.57 & رغم وجود المحتوى الرقمي العربي الذي أحتاجه على شبكة الإنترنت إلا أنني أجد صعوبة \\
\hline 1.044 & 2.59 & بمناز المحتوى العلمي العربي على الإنترنت بالتنوع في الثكل والمو اضيع \\
\hline .974 & 2.43 & يلبي المحتوى الرقمي العربي كافة احتياجاتي المعلوماتية البحثية \\
\hline .931 & 2.17 & أجد كل المعلومات التي أحتاجها متاحة باللغة العربية \\
\hline
\end{tabular}

\section{مجالات استخدام المحتوى الرقمي العربي على شبكة الإنترنت:}

يوضح جدول (6) أن جميع العبار ات الخاصة بمجالات استخدام المحتوى الرقمي العربي حصلت على قيم متوسطة مما يدل على أن عينة الدر اسة لم تتفق بشكل كبير مع العبارات فنجد أن عبارة استخدام المحتوى العربي لاعم نتائج الدراسات حصلت على أعلى منوسط بقيمة 3.76 بينما حصدت العبارات الخاصة بزيادة المعرفة والورش العلمية وزيادة نسبة المحتوى على المركز

$$
\text { الثاني و الثالث و الر ابع بمتوسطات تر اوحت بين } 3.56 \text { إلى 3.6. }
$$

يُلاحظ أيضا وجود اتفاق بشكل متوسط في استخدام المحتوى الرقمي العربي في التدريس حيث حصلت على منوسط 3.54 بينما حلت العبار ات الخاصة بمتابعة التطور ات في المجال وتأليف الكتب ودعم نتائج الدر اسات الأجنبية على الثلاث مر اكز الأخيرة بقيم تتراوح بين 3.28 إلى 3.42. وبعمل اختبار test لكثف وجود فروق ذات دلالة إحصائية بين الذكور والإناث حول استخدامات المحتوى الرقمي العربي على شبكة الإنترنت وجد فروق ذات دلالة إحصائية في عبارة واحدة وهي " أستخدم المحتوى الرقمي العربي لمتابعة آخر المستجدات في المجال" حيث بلغت قيمة T-3.502 عند مستوى دلالي 0.001. 


$$
\text { جدول (6) مجالات استخدام المحتوى الرقمي العربي على شبكة الإنترنت }
$$

\begin{tabular}{|c|c|c|}
\hline الانحر اف المعياري & المتوسط & 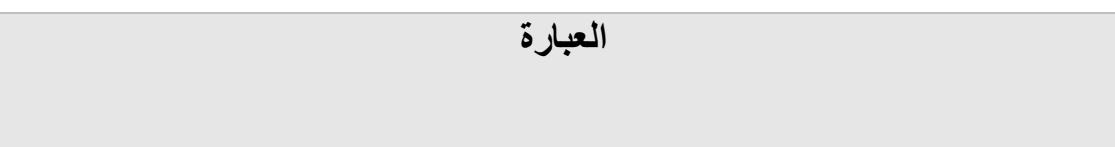 \\
\hline .931 & 3.76 & أستخدم المحتوى الرقمي العربي لدعم نتائج در اساتي العلمية العربية \\
\hline .905 & 3.60 & أستخدم المحتوى العربي لزيادة المعرفة وزيادة المحتوى العربي في قو اعد عربية بحتة \\
\hline .951 & 3.59 & أستخدم المحتوى الرقمي العربي للورش العلمية \\
\hline .886 & 3.56 & أستخدم المحتوى الرقمي في تمكين وزيادة نسبة المحتوى الرقمي بالعربية على شبكة \\
\hline .965 & 3.54 & أستخدم المحتوى الرقمي العربي في التدريس \\
\hline 1.226 & 3.42 & أستخدم المحتوى الرقمي العربي لمتابعة آخر المستجدات في المجال \\
\hline 1.125 & 3.31 & أستخدم المحتوى الرقمي العربي في تأليف الكتب \\
\hline 1.072 & 3.28 & أستخدم المحتوى الرقمي العربي لدعم نتائج در اساتي العلمية الإنجليزية \\
\hline
\end{tabular}

\section{معاييز ملاءمة المحتوى الرقمي:}

بتحليل جدول (7) الخاص بمعايير ملاءمة المحتوى الرقمي العربي لاحتباجات الباحثين نجد حصول ثلاث عبارات على متوسطات عالية و هي العبار ات الخاصة بصلة النشاط البحثي (4.10) و العبارة الخاصة بجهة إصدار المحتوى (4.10) و أيضا العبارة الخاصة باسم المجلة العلمية المنتجة لذلك المحتوى (4.07)

أيضا حل في المركز الر ابع سمعة قاعدة البيانات التي تنشر ذللك المحتوى (3.99) وأصلالة المحتوى في المركز الخامس (3.97) وفي المركز السادس انتساب منشئ العمل لمؤسسة ذات سمعة طيبة (3.96). بينما حصلت معايير أخرى على قيم مرتفعة نِنِيًَّا مثل اسم منشئ العمل (3.72) وتخصص الباحث عن المحتوى (3.36). بينما حصلت العبارة الخاصة بإجادة اللغة الإنجليزية على منوسط ضعيف وحلت في المركز الأخير مما يدل على عدم اتفاق العينة مع العبارة (2.88). وبعمل اختبار test لكثف وجود فروق ذات دلالة إحصائية بين الذكور و الإناث حول المعايير التي تحدد ملاعمة المحتوى الرقمي للاعنماد عليها كمصدر للمعلومات وجد فروق ذات دلالة إحصائية في عبارة و احدة وهي " حداثة الموضوع و عدم وجود 
بديل له باللغة الإنجليزية يؤثر بشكل كبير على استخدامي للمحتوى الرقمي العربي" حيث بلغت قيمة T-3.000 عند مستوى دلالي 003.

$$
\text { جدول (7) معايير ملاءمة المحتوى الرقمي }
$$

\begin{tabular}{|c|c|c|}
\hline الانحر اف & المتوسط & 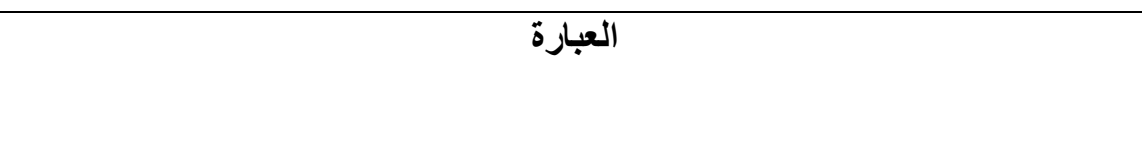 \\
\hline 1.070 & 4.10 & 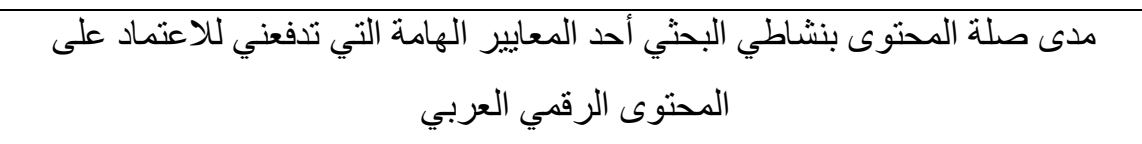 \\
\hline 1.060 & 4.10 & صدور المحتوى عن جهة لها ثقلها في المجال له نأثثر على مدى اعتمادي على المحتوى العربي \\
\hline 1.048 & 4.07 & اسم المجلة العلمية يؤثر بشكل كبير على استخدامي للمحتوى الرقمي العربي \\
\hline .979 & 3.99 & اسم قاعدة البيانات يؤثر بشكل كبير على استخدامي للمحتوى الرقمي العربي \\
\hline 1.144 & 3.97 & أصلالة المحتوى أحد المعايير الهامة التي تدفعني للاعتماد على المحتوى الرقمي العربي \\
\hline 1.004 & 3.96 & انتماء منشئ العمل لمؤسسة لها سمعة طيبة أعتبره معيار الجودة أعماله البحثية \\
\hline 1.102 & 3.96 & حداثة الموضوع و عدم وجود بديل له باللغة الإنجليزية يؤثر بشكل كبير على استخدامي للمحتى الرقمي العربي \\
\hline 1.129 & 3.72 & اسم منشئ المحتوى (المؤلف) يؤثر بشكل كبير على استخدامي للمحتوى الرقمي العربي \\
\hline 1.254 & 3.36 & تخصصي العلمي يؤثر بشكل كبير على استخدامي للمحتوى الرقمي العربي \\
\hline 1.310 & 2.88 & 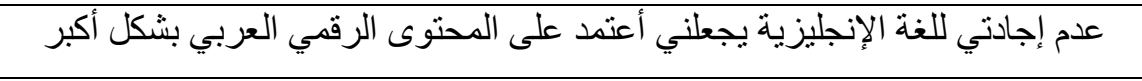 \\
\hline
\end{tabular}

مناقشة النتائج والتوصيات:

أولاً مناقشة النتائج:

\section{جودة وموثوقية المحتوى الرقمي العربي من وجهة نظر الباحثين العرب:}

أفضت الدر اسة إلى نتائج مختلفة حول جودة وموثوقية وملاءمة المحتوى الرقمي العربي مما قد يساعد في صناعة واستدامة المحتوى الرقمي العربي عمو ما لما له من أهمية قصوى على مستويات مختلفة تشمل البحثية و الثقافية و الأدبية و الاقتصادية. حيث أوضحت النتائج الديموغر افية أن غالبية العينة من الباحثين العمانيين الثباب من الأساتذة المساعدين، وأن معظمه لديهم خبرة بحثية تزيد عن العشر سنوات في تخصصات الآداب و العلوم الإنسانية، كما أشارت أيضا إلى أن محرك البحث جو جل هو محرك 
البحث الأساسي المستخدم من قبل غالبية العينة و هي نتائج تطابقت مع نتائج الدر اسة الخاصة بـ Zook (2016) التي تثير إلى أن جلّ الباحثين الثباب يلجؤون إلى محرك البحث جو جل بالذات المتخصص في الأدب العلمي في كل أبحاثهم لثقتهم الكبيرة فيه. توصلت الدراسة إلى ضعف مصادر المعلومات المتاحة باللغة العربية على كل المستويات و الأنواع سو اء كانت رسائل جامعية، كتب علمية، المراجع العلمية، القو اميس، المخطوطات والموسو عات، أو قواعد بيانات، وهو ما يعاني منه كل الباحثين العرب حسب ما توصل إليه الباحث نبال (2018) حيث ذكر أنها لا ترقى لمستوى ترتيب اللغة العربية والعرب في استخدام تكنولوجيا تقنية المعلومات و الاتصال حيث إنهم الأكثر استهلاكا لها.

فيما يخص موثوقية المحتوى الرقمي العلمي العربي على شبكة الإنترنت أشارت النتائج إلى تفوق المصادر الأجنبية على العربية من حيث الموثوقية، حيث ذكر عدد كبير من عينة الدراسة أن ناشري المحتوى الرقمي العلمي العربي لا يهتمون ولا يدققون في فحص المحتوى لمعرفة أصلة وموثوقية ونسبة الانتحال في المحتوى العربي كما تحفظ العديد من أفر اد العينة على جودة و أصلالة المحتوى الرقمي العربي مما ينعكس سلبا على مدى اعتماد الباحثين والمهتمين بتلك المصادر. أيضا كان هناك عدم اتفاق من عينة الدراسة حول صحة المعلومات العلمية العربية المنثورة على شبكة الإنترنت وثتتهم في معظم مصادر المعلومات العربية العلمية على شبكة الإنترنت. هذه النتائج تتطابق مع تقرير الإسكوا (2012) الذي يؤكد ندرة مصادر المعلومات باللغة العربية نتيجة لعدم ثقة الباحثين العرب على اعتماد تلك المصادر مما أدى إلى قلتها وندرنها. ويؤكد الباحثون أنه من الضرورة وضع استر اتيجية عربية شاملة لصناعة المحتوى الرقمي العربي و إعادة الثقة إلى المستفيدين منها، وحث كل الدول العربية للانخر اط في هذا المشروع الضخم، بما تملك من إمكانات بشرية و أدبية وعلمية وثقافية واقتصادية مهولة. وما يعطي قيمة كبيرة لهذا العمل، كون اللغة العربية تعد لغة رسمية في جميع الأقطار العربية دون استثناء وذات صيت كبير بين لغات العالم. تلبية المحتوى الرقمي العربي الحالي للاحتياجات والخذمات المعلوماتية:

في جزئية تلبية المحتوى الرقمي العربي لاحتياجات الباحثين العرب، توصلت الدراسة إلى أن جل العينة أكد على عدم تلبية المحتوى الرقمي لاحتياجاتهم البحثية حيث ذكر عدد كبير منهم أن المحتوى الرقمي المتاح بلغات أخرى كالإنجليزية أكثر وفرة وتتوعًا عن المحتوى العلمي العربي لتلبية احتياجات الباحثين العرب كما أشار عدد منهم إلى أنه يو جد ندرة في المحتوى العربي العلمي في كثير من التخصصات العلية بالذات الحديثة منها مما يؤكد عدم تلبية المحتوى العربي لاحتياجات الباحثين العرب. هذه النتائج نتو افق مع توصيات ورشة العمل الافتراضية حول صناعة محتوى رقمي عربي التي أدارها د. نبيل علي الصالح - 
ARID International Journal of Informetrics and Scholarly Communication (AIJISC) VOL: 3, NO 4, January 2022

2007 وأيضا دراسة نبيل (2018) والتي ركزت على أن المحتوى العربي الرقمي لا يلبي احتياجات وتطلعات الباحثين و المستفيدين العرب إما لقلتها أو لندرتها أو و عدم موثوقية ما يتاح منها.

\section{استخدامات الباحثين العرب للمحتوى العربي الرقمي على شبكة الإتترنت:}

أظهرت النتائج أن هناك قلة في مجالات استخدام المحتوى الرقمي العربي على شبكة الإنترنت حيث أظهرت النتائج أنها تتلخص في عدد من المجالات منها أنها تستخدم لدعم نتائج الدر اسات، وزيادة المعرفة ودعم الورش العلمية وزيادة نسبة المحتوى العربي، و واستخدام المحتوى الرقمي العربي في التدريس واستخدام المحتوى الرقمي العربي لمتابعة آخر المستجدات في المجالات المختلفة، وتتفق هذه النتيجة مع بحث أجرته القبلان (2007) يشير إلى قلة استخدام المحتوى العرب لعدد من الأسباب منها عدم التقييم الصحيح لمصدر المعلومات بسبب عدم الثقة بالوسيط، ويضيف الباحثون أن عدم اهتمام القائمين على الأمر ومتخذي القرار فيما يخص تجويد وانتشار المحتوى العربي الرقمي عموما يضعف من جودة المحتوى العربي المتاح للباحثين. المعايير التي تحدد ملاعمة المحتوى الرقمي للاعتماد عليها كمصدر للمعلومات:

كثفت الدراسة أن معايير ملاءمة المحتوى الرقمي العربي رغم قلتها تتركز في اسم منشئ العمل وتخصص الباحث، إلا أن معيار مدى صلة المحتوى بالنشاطات البحثية العلمية يأتي في المقام الأول ومن ثم معيار صدور المحتوى عن جهة لها ثقلها في المجال المختص وله تأثئر على مدى اعتماده على المحتوى العربي ومن ثم معيار اسم المجلة العلمية وقاعدة البيانات المنتجة لذلك المحتوى. هناك معايير أخرى أنشارت إليها الدراسة بنسب أقل وهي سمعة قاعدة البيانات التي تنتر ذلك المحتوى وأصالتها، و انتساب منشئ العمل لمؤسسة ذات سمعة طيبة بينما حصل معيار إجادة اللغة الإنجليزية على منوسط ضعيف وحل في المركز الأخير مما يدل على عدم اتفاق العينة مع العبارة. هذه النتيجة مدعومة من قبل الإسكوا (2012) حيث أثنارت إلى أن أهم المعايير التي تستخدم لملاءمة المحتوى الرقمي العربي تتلخص في مدى موثوقية واسم الجهات التي تصدر عنها تلك المصادر بالإضافة إلى اسم المصدر وتثقله بين الجهات الأكاديمية ويؤكد الباحثون على تللك النتائج أن معايير ملاءمة المحتوى الرقمي تعتمد على مدى حداثة الموضوع و عدم وجود بديل له باللغة الإنجليزية يؤثر بشكل كبير على استخدامي للمحتوى الرقمي العربي.

في ضوء ما تمّ التوصل إليه من نتائج نثير بأن الدراسة توصلت إلى عدد من النتائج الهامة و التني تتلخص أن المحتوى العربي على شبكة الإنترنت ماز ال غير قادر على منافسة المحتوى المتاح بلغات أخرى. وتوصي الدراسة بالآتي: 
1. على القائمين بأمر المحتوى الرقمي العربي الاهتمام ببناء مجتمع معلوماتي عربي قوي من خلال التركيز على

$$
\text { استخدام تقنية المعلومات والاتصالات وتأسيس صناعة عربية رقمية بحتة. }
$$

2. ضرورة وضع آلية لزيادة الخصوصية والموثوقية للمحتوى العربي الرقمي ويمكن أن تقوم جهات الاختصاص من الوزارات المعنية وشركات الاتصالات بهذا الدور.

3. ضرورة أن تقوم المؤسسات الأكاديمية والمساعدة لها بتفعيل دور البحث العلمي في تعزيز المحتوى المعرفي

$$
\text { الرقمي العربي بتثجيع ودعم البحوث العلمية العربية. }
$$

4. الاعتر اف بحاجتنا الماسة لنهضة لغوية شاملة، القادرة على تلبية مطالب ومقتضيات العصر، بشرط أن لا يلقى ذللك على عاتق اللغويين فقط، بل لابد من اشتراك كل المعنيين. 5. ضرورة وضع استر اتيجية عربية شاملة لصناعة المحتوى الرقمي، وحث كل الأقطار العربية للمشاركة بفاعلية في هذا المشروع الضخم، بما تملك من معطيات أدبية وعلمية وثقافية و اقتصادية. وما يعطي قيمة كبيرة لكل ذلك، كون اللغة العربية تعد لغة رسمية في جميع الأقطار العربية. 6. يجب وضع معايير قياسية ملاءمة خاصة بالمحتوى الرقي العربي أسوة بالمعايير العالمبة المماتلة. 
الإسكوا (2007). توصبات ورشة العمل الافتراضية حول صناعة محتوى رقهي عربي التي ادر ها د. نبيل علي الصالح. 33 مسترجع من /http://www.escwa.org.lb/divisions/ictd/workshop/forum_a

بادي، سو هام، بادي، سامية. (2020). إثراء المحتوى الرقمي العربي من خلال المنصات الإلكترونية العربية إللغة العربية: الدجلس الأعلى

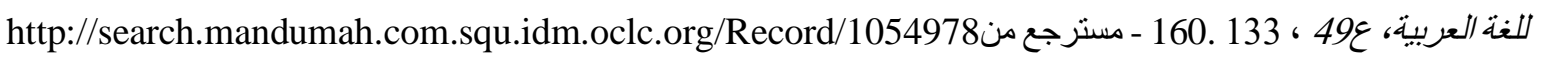
بادي، سو هام، بو خالفة، خديجة. (2018). خصائص البنية التحتيّة الداعمة لإنتاج المحتوى الرقمي في دول المغرب العربي .اعلم: الاتحاد

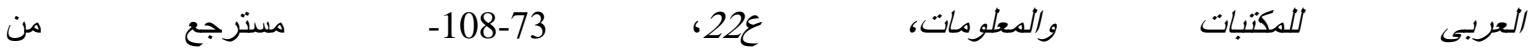
http://search.mandumah.com.squ.idm.oclc.org/Record/970648 بن السبتي، عبدالماللك، بن السبتي، سارة. (2017). المحتوى الرقمي العربي ومستقبل مهنة المعلومات في مجتمع المعرفة المؤتمر الثامن: مؤسسات الدعلومات في المدلكة العربية السعودية ودورها في دعم اقتصاد ومجتدع الدعرفة. المسؤوليات. التحديات. الآليات. التطلعات: الجمعية السعودية للمكتبات والمعلومات، الرياض: جمعية المكتبات و المعلومات السعودية، مج2 ، 401 - 428. مسترجع http://search.mandumah.com.squ.idm.oclc.org/Record/839634 منسع بن جامع، بلال، مهري، سهيلة. (2019). دور برامج تدفق المعلومات في تفعيل مشاريع الرقمنة: در اسة بدائرة أرشيف سوناطر الك مجلة

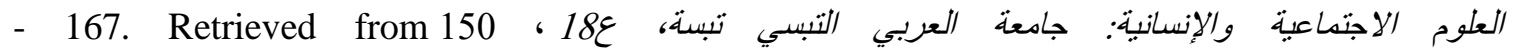
http://search.mandumah.com.squ.idm.oclc.org/Record/1057111

جمعة، نصر الدين حسن أحمد. (2017). المحتوى العربي وتحديات الوصول إلى مجتمع المعرفة مبادرة المركز القومي للبحوث ـمركز التوثيق والمعلومات: دراسة حالة .المؤتدر الثامن: مؤسسات المعلومات في المدلكة العربية السعودية ودورها في دعم اقتصاد ومجتمع الدعرفة. المسؤوليات. التحديات. الآليات. التطلعات: الجمعية السعودية للمكتبات والمعلومات، الرياض: جمعية المكتبات

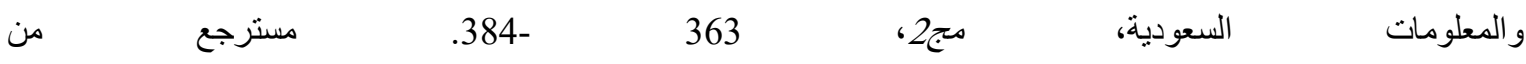

http://search.mandumah.com.squ.idm.oclc.org/Record/839624

الحافظ، نزار. (2019). واقع اللغة العربية في عصرنا الحاضر. المؤتمر السنوي العانر لمجمع اللغة العربية بدمثق 28-2019/2/26 حسني، عبد الرحمان، و بن السبتي، عبدالمالك. (2018). واقع المحتوى الرقمي العربي في نظر أعضاء التدريس في جامعة محمد خيضر

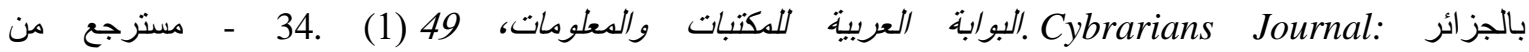
http://search.mandumah.com.squ.idm.oclc.org/Record/961677

زايدي، غنية. (2018). محركات البحث بين ضرورات التنظيم وتحديات الوصول الى المحتوى العربي .مجلة مقاربات. مؤسسة مقاربات

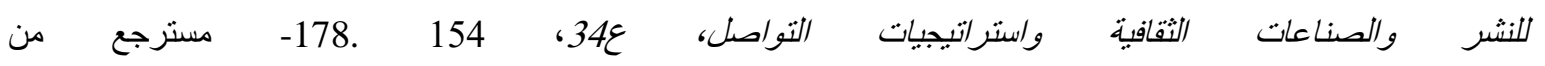
http://search.mandumah.com.squ.idm.oclc.org/Record/872002 السالم، سالم بن محمد. (2010). إثكاليات صناعة المحتوى الرقمي العربي مؤتعر المحتوى العربي في الانترنت ـالتحديات والطموح: جامعة الإمام محد بن سعود الاسلاميةالرياض: جامعة الإمام محمد بن سعود الإسلامية، مج 1، 17 -63. مسترجع من http://search.mandumah.com.squ.idm.oclc.org/Record/101277 
ARID International Journal of Informetrics and Scholarly Communication (AIJISC) VOL: 3, NO 4, January 2022

السالم، سالم بن محمد. (2011). صناعة المحتوى الرقمي العربي: و الإشكالات المعاصرة بحلة دراسات المعلومات: جمعبة المكتبات http://search.mandumah.com.squ.idm.oclc.org/Record/94949 والمعلومات السعودية، ع 10 مسترجع من السالم، سالم بن محمد. (2012). المحتوى العربي في الانترنت بمجلة دراسات المعلومات: جدعية المكتبات والمعلومات السعودية، ع 13 http://search.mandumah.com.squ.idm.oclc.org/Record/206807 مسترجع من.

عبد الو احد، محمد نجيب (2018,ايلول). أهمية ودور المحتوى التعليمي الرقمي في إحداث التغيير المنشود في قطاع التعليم العالي في سوريا، ورقة مقدمة إلى المؤتمر الثاني لصناعة المحتوى الرقمي العربي المحتوى المعرفي السوري، دمثن، تم الاسترجاع من الر ابط: https://acnc.svuonline.org/ar

علوي، هند، ومحمود، مسروة. (2017). المحتوى الرقمي العربي عبر شبكة الإنترنت: اقتراح تصميم بوابة عربية لإدارة المحتوى الرقمي .المجلة الأردنبة للمكتبات والمعلومات: جدعبة المكتبات والدعلومات الأردنية، 52( 3) ، 11 .40 - مسترجع من 11 . http://search.mandumah.com.squ.idm.oclc.org/Record/835337

علوي، هند، و مسروة، محمود عبدالقادر. (2020). اقتراح تصميم بوابة لإدارة المحتوى الرقمي العربي بمجلة العلوم الإنسانية: جامعة منتوري http://search.mandumah.com.squ.idm.oclc.org/Record/1064662

القبلان، \& , . , العبد .(2007) .الوصول الحر للمعلومات: دراسة لاتجاهات الأكاديميين في الجامعات السعودية لنشر إنتاجهم الفكري عبر الإنترنت .المؤتمر الثامن عثر للاتحاد العربي للمكتبات والمعلومات (اعلم): مهنة المكتبات وتحديات الواقع و المستقبل و دور ها في الوصول الحر للمعلومات العلمية، جدة (السعودية) 17-20 نوفمبر 32.2007-1 ,

محمود، محمد عبدالمولى. (2011). المحتوى العربى على الإنترنت: دراسة و يبومترية (در اسة دكتور اه، جامعة القاهرة، القاهرة).- متاح http://erepository.cu.edu.eg/index.php/cutheses/thesis/view/1573 من خلا

Aita, Samir. (2012). Status of the Digital Arabic Content Industry in the Arab Region. 10.13140/Rg.2.2.16677.76006

Fu, L. Y., Zook, K., Spoehr-Labutta, Z., Hu, P., \& Joseph, J. G. (2016). Search Engine Ranking, Quality, and Content of Web Pages That Are Critical Versus Noncritical of Human Papillomavirus Vaccine. J Adolesc Health, 58(1), 33-39. https://doi.org/10.1016/j.jadohealth.2015.09.016 